\title{
A pecuária de leite bovino numa (re)análise: perspectivas e impasses no Brasil
}

\author{
Bovine milk livestock in a (re)analysis: perspectives and impasses in Brazil
}

\author{
Thales Silveira Souto \\ Doutorando em Geografia no Programa de Pós-Graduação em Geografia \\ Universidade Federal de Santa Maria (PPGGEO/UFSM), Brasil \\ thales.souto@hotmail.com \\ Ivanio Folmer \\ Doutorando em Geografia no Programa de Pós-Graduação em Geografia \\ Universidade Federal de Santa Maria (PPGGEO/UFSM), Brasil \\ ivaniofolmer@yahoo.com.br
}

\section{Resumo}

A pecuária de leite bovino historicamente possui importância para a organização política, econômica e social do país. Todavia, deve-se levar em consideração algumas dificuldades que os produtores de leite vivem, as quais são permeadas pelo escasso auxílio e crédito, como também, a pouca valorização desta produção frente os demais setores produtivos, ocasionando os impasses para um maior incremento e desenvolvimento. Desta forma, este estudo tem como alvo de verificação a produção de leite bovino no Brasil no período de 1977 a 2017. As reflexões possibilitadas nessa investigação nos direcionam para a compreensão das inquietações que move esse setor produtivo, entendendo as preocupações, as aflições e, em alguns casos, o sucesso dos produtores de leite.

Palavras-chave: Pecuária de Leite Bovino; Políticas Públicas; Brasil.

\begin{abstract}
Cattle raising for cattle have historically been necessary for the country's political, economic and social organization. However, one must take into account some difficulties that milk producers are experiencing, which are permeated by scarce aid and credit, as well as the little appreciation of this product concerning the other productive sectors, causing impasses for higher growth and development. Thus, this study aims to verify the production of bovine milk in Brazil from 1977 to 2017. The reflections made possible in this investigation lead us to understand the concerns that move this productive sector, understanding the concerns, the afflictions and, in some cases, the success of milk producers.
\end{abstract}

Keywords: Cattle Raising; Public Policy; Brazil.

\section{INTRODUÇÃO}

A partir do desenvolvimento de pesquisas científicas, juntamente com o aprimoramento das técnicas e a implementação de equipamentos com maior complexidade de elaboração no processo produtivo, promoveram evoluções na pecuária de leite bovino. Entretanto, reconhece-se que as políticas públicas e as ações do capital privado foram "tímidas" para esta atividade. Tal fato é resultado da atenção ofertada ao setor agrícola. (SOUTO, 2016).

A pecuária de leite bovino foi e ainda continua sendo importante para a organização política, econômica e social do país. Na premissa do valor que este setor produtivo exerce, deve-se 
levar em consideração algumas dificuldades que os produtores de leite vivem, as quais são permeadas pelo escasso auxílio e crédito, como também, a pouca valorização desta produção frente os demais setores produtivos, ocasionando os entraves para um maior incremento e desenvolvimento.

Ao verificar a produção de leite bovino no painel mundial, ressalta-se que a produção brasileira está sob forte concorrência nos quesitos de quantidade, qualidade, produtividade e custos de produção. Enfatiza-se que no ano de 2018, os maiores produtores do mundo foram: Estados Unidos da América (98.690.477 toneladas), Índia (89.833.590 t.), Brasil (33.839.864 t.) e China (31.165.090 t.). FAOSTAT (2018).

Levando em consideração a produção de leite bovino no Brasil, de acordo com a Pesquisa Pecuária Municipal (disponível no Sistema IBGE de Recuperação Automática - SIDRA/IBGE, 2018) no ano de 2018 foram produzidos 33,8 bilhões de litros de leite bovino, com mais de 16,3 milhões de vacas ordenhadas. Desmembrando essa produção entre os estados brasileiros, salientamse os três maiores produtores. Em primeiro lugar, encontra-se o estado de Minas Gerais, com uma produção de 8,9 bilhões de litros de leite, seguido pelo Paraná com 4,3 bilhões de litros e Rio Grande do Sul, com 4,2 bilhões de litros. (IBGE, 2018).

Em relação a quantidade de vacas ordenhadas, aponta-se os três estados com os maiores números, Minas Gerais, com o total de 3,1 milhões de vacas ordenhadas, seguido por Goiás, com o total de 1,9 milhões e Paraná, com o total de 1,3 milhões de vacas ordenhadas. (IBGE, 2018).

Neste panorama, algumas questões podem ser levantadas ao tratar da relevância deste setor no Brasil, como: qual a importância desta atividade frente as demais produções agropecuárias; quais são as perspectivas e os entraves para o incremento da pecuária leiteira no país; qual é a realidade vivenciada dos produtores menos capitalizados, os quais possuem importância na esfera produtiva, social e econômica local.

Destarte, este estudo tem como alvo de verificação a produção de leite bovino no Brasil. A problemática deste estudo se alicerça na verificação do cenário produtivo de leite no período de 1977 a 2017. Infere-se que este setor produtivo está passando por transformações, como relacionado a redução de área (ha) para o cultivo de pastagem, a diminuição do número de vacas ordenhadas, a expansão da produtividade, a expansão da instalação de laticínios e unidades receptoras de leite in natura. Salienta-se ainda as ações e políticas que conduziram o crescimento do setor agrícola, como da soja e da cana-de-açúcar, culminando na redução de áreas (ha) para o cultivo de culturas tradicionais (arroz, feijão, batata e outros), bem como, do setor pecuário como o bovino, na escala temporal de 1977 a 2017.

Esta investigação é vinculada a um campo que já é bastante difundido e tem grande contribuição na ciência geográfica, que é a Geografia Agrária. Todavia, novas investigações na área 
de pesquisa proporcionam renovação e criam novas possibilidades de pensar a organização do espaço agrário contemporâneo, considerando a dinâmica da relação sociedade e natureza.

A este respeito, para a organização deste estudo, elaborou-se as seguintes etapas metodológicas. A primeira etapa referiu-se a revisão bibliográfica. A segunda etapa realizou-se a coleta de dados secundários do Sistema IBGE de Recuperação Automática (SIDRA) por meio da Pesquisa Pecuária Municipal (PAM) no período de 1977 a 2017 (período que apresenta dados anuais desta atividade). Posteriormente analisou-se os dados e as informações produzidas, possibilitando a interpretação das perspectivas e dos impasses deste setor produtivo.

Todavia, destaca-se que a produção do objeto de estudo é dinâmica, ou seja, se transforma diante das diferentes realidades observadas in loco. Na sequência do artigo ocorre as discussões teóricas que nos respaldaram na análise e, sobretudo, na compreensão das organizações/reorganizações socioespaciais a partir do entendimento dos processos que estabeleceram o desenvolvimento da agricultura no Brasil, como também, os impactos decorrentes desta atividade.

O referencial teórico deste estudo foi organizado a partir dos seguintes títulos: A produção/reprodução do espaço mediada pelas tendências do capital na agricultura e; A pecuária de leite bovino frente as limitações, as dificuldades e as expectativas para o desenvolvimento local/regional. Salienta-se que os dois títulos apresentados possuem a finalidade de maximizar e enfocar as informações diante do cenário estudado.

As reflexões possibilitadas pelas leituras das obras que buscaram interpretar, analisar e descrever as transformações socioespaciais resultantes das ações públicas e privadas para a organização espacial brasileira foram essenciais para auxiliar na interpretação dos dados secundários referentes a pecuária de leite bovino.

\section{A PRODUÇÃO/REPRODUÇÃO DO ESPAÇO MEDIADA PELAS TENDÊNCIAS DO CAPITAL NA AGRICULTURA}

A transformação espacial tem sido viabilizada pelas demandas do capital, as quais em muitos casos podem ser formalizadas pelas ações, medidas e políticas públicas. A este respeito, salienta-se que a articulação e o movimento que a produção capitalista veementemente promove na sociedade é um processo que se deve interpretar para entender os artifícios que estão engendrados na relação com o meio, gerando diferentes organizações tanto no domínio rural quanto no urbano.

O desenvolvimento das atividades produtivas na cidade e no campo, mais especificamente, nos setores primário, secundário e terciário, ou seja, por meio do trabalho do homem e a relação que este tem no decorrer dos diferentes momentos de sua história, engrena a metamorfose espacial. Desta forma, Moreira (1982, p.88) ressalta que, “Como é o espaço produzido pelo trabalho, o 
espaço geográfico é, a um só tempo, resultado e agente impulsor do desenvolvimento da história dos homens".

Desvendar a transformação do espaço pela reprodução das atividades capitalistas de produção é essencial para compreender as alterações resultantes no mesmo, como também, para verificar a história dos homens. Neste sentido, Moreira (1982, p. 89) completa,

Uma vez que a história dos homens é a história dos homens concretos e o espaço geográfico é um espaço historicamente produzido, o que nele vemos é a própria história. O espaço é a sociedade, e a revela por inteiro. É esplêndido recurso de "leitura" da sociedade. E a leitura, invariavelmente, será feita pelos óculos ideológicos de quem a faz: "óculos empíricos" ou "óculos dialéticos".

A este respeito, a relação espaço/sociedade deve ser discutida. Diante disto, Barrios (1986, p. 2) propõe que o espaço possui duas funções básicas como elemento físico "[...] de objeto da atividade humana (recursos naturais) e a de suporte dessa mesma atividade (meio ambiente)". Sendo assim, tanto o papel do espaço como objeto quanto de suporte para o homem, imprimem a sua importância para o desenvolvimento dos diferentes grupos.

Sobre as práticas espaciais e as reformulações elaboradas pelos homens, deve-se valorizar que, o homem como sujeito da história desenvolveu as suas habilidades e, por conseguinte, as suas práticas, incrementando as formas de uso e ocupação no espaço. Neste sentido, em cada momento específico houve a configuração do espaço e, consequentemente, os objetos presentes neste também foram munidos de reformulações, pois o objeto é apropriado de um modo específico pelo espaço preexistente. (SANTOS, 2006).

As transformações do meio, o aprimoramento das técnicas e o desenvolvimento de tecnologias serão congruentes às necessidades dos grupos dominantes. Nessa dinâmica, ressalta-se que o espaço que sofreu alterações é a resposta não apenas da evolução da humanidade, mas sobretudo, como produto instituído pelos dominadores.

O monopólio da produção do espaço pelos grupos dominantes formula as desigualdades que serão impressas em vários formatos, os quais podem ser relacionados as diferenças entre as técnicas adotadas por um grupo às tecnologias inseridas por outro grupo. Tal princípio revela as peculiaridades no processo de produção, apropriação e acumulação, os quais são desiguais.

Nos distintos momentos da transformação do espaço, por meio das práticas econômicas e sociais, o homem produziu, distribuiu e consumiu os meios materiais. Neste processo, têm-se a utilização de tecnologias e a relação entre os homens que fazem parte desse processo. Neste sentido, Elias (2005, p. 227) ressalva que,

Vivemos, nos últimos cinquenta anos, um processo acelerado de transformações de diversas naturezas, magnitudes e complexidades, caracterizando um novo momento do capitalismo, que recebe diversas denominações e conta com diferentes interpretações, muitas vezes dispares e conflitantes entre si. 
Nesta perspectiva, cabe apontar que a transformação do meio pelo homem é uma realidade que vem sendo promovida e disseminada a partir do momento em que o homem se apoderou e aperfeiçoou as técnicas. Entretanto, é sabido que o aperfeiçoamento das mesmas não aconteceu/acontece de forma homogênea em todo o planeta.

O aprimoramento das técnicas, a ampliação do uso e ocupação do solo, juntamente, com o incremento tecnológico proporcionaram a expansão produtiva de todos os setores. A este respeito, Elias (2005, p. 230) aponta que,

Com o acirramento da globalização da produção e do consumo, difundem-se, mais rapidamente, as bases materiais que possibilitaram a dispersão espacial da produção. $\mathrm{O}$ avanço dos transportes e das comunicações viabiliza fluxos, de matéria e de informação, até então inimagináveis. Isto é tão verdade que a instantaneidade e a simultaneidade são signos do presente. Isto faz com que o espaço da produção em geral, inclusive agrícola, amplie-se, passando a incluir áreas que até então se mostravam pouco propícias à realização de alta lucratividade.

A dispersão espacial da produção juntamente com o avanço dos transportes e das comunicações foi fundamental para o sucesso produtivo atual. Neste panorama, deve-se apontar o cenário da produção agropecuária, bem como, a mudança na sua estrutura técnica, organizacional e a inserção de aparatos tecnológicos para o seu aprimoramento e ampliação.

Portanto, a produção exacerbada e o consumo exagerado são reflexos do desenvolvimento e da transformação da economia. Sendo assim, refletir sobre a sociedade que gera desde os impactos ambientais aos abismos sociais é fundamental para entendermos o desenvolvimento da história atual.

Para tanto, deve-se fazer uma revisão do processo dinamizador e articulador do cenário produtivo da atualidade. Nesta trama, aponta-se a modernização das atividades produtivas agropecuárias, as quais proporcionaram impactos de diferentes magnitudes e complexidades tanto no meio rural quanto no urbano.

O aprimoramento dos instrumentos técnicos desencadeou a evolução das tecnologias, bem como, a dispersão das mesmas em diferentes períodos históricos e intensidades no espaço geográfico. Nesta perspectiva, deve-se destacar que um dos fatores da metamorfose socioespacial foi a evolução das tecnologias e sua inserção no campo.

As inovações na atividade agropecuária vão ao encontro com o incremento e a evolução das técnicas, uma vez que, de acordo com as necessidades de determinado momento da história, o homem teve que se adaptar ou até mesmo buscar novas formas de produção para atender as suas demandas.

Entretanto, o incremento produtivo de algumas atividades agrícolas foi possível devido a inserção do interesse dos grupos dominantes. Tal empenho permanece como um dos principais movimentos balizadores da concentração do poder pelas corporações transnacionais, que possuem 
suas sedes nos países desenvolvidos e as suas unidades industriais, bem como, os seus mercados consumidores, em sua maioria, nos países periféricos.

Ao abordar os artifícios da ampliação do setor produtivo agropecuário, destaca-se que esse movimento proporcionou a expansão para algumas culturas agrícolas, bem como, a redução, ou até mesmo, a marginalização para determinadas atividades produtivas no meio rural. Dessa forma, apontam-se que na atualidade, é fundamental abordar o incremento da agricultura e o crescimento exponencial da produtividade de algumas culturas agrícolas, como também, os impactos socioespaciais resultantes deste processo, pois é uma realidade persistente frente às demandas da sociedade.

Todavia, a partir da metade do século XX, enfatiza-se que a evolução do setor agropecuário, mediada pela maximização produtiva, ocorreu não apenas para atender a demanda da população mundial por alimentos, a qual estava se tornando cada vez mais urbana, mas, sobretudo, para ir de encontro com a necessidade das corporações internacionais, visando maior produção e acumulação do capital.

A este respeito, ressalta-se o processo de modernização da agricultura. Esta fase de desenvolvimento foi consolidada devido a solidificação dos Estados Unidos da América (EUA) no mundo capitalista, principalmente, a partir do término da $2^{\mathrm{a}}$ Guerra Mundial (1939-1945). Assim, profundas mudanças econômicas e produtivas foram resultantes (BRUM, 1988).

A agricultura, portanto, teve no bojo do processo de incremento produtivo a incessante necessidade de se industrializar. Tal artifício foi articulador do crescimento exponencial da produção de algumas culturas agrícolas, como trigo, milho, soja, entre outros cultivos e, posteriormente, para o setor pecuário.

Embora os investimentos para o desenvolvimento da produção industrial tenham ocorrido com maior ênfase nos países centrais. Faz-se importante considerar que, o sucesso das multinacionais e das suas articulações no cenário econômico mundial é imbricado a expansão e inserção do capital nos países periféricos.

Todavia, aponta-se que o capital internacional por si só não conseguiria com facilidade, em um primeiro momento, promover toda a mudança no panorama produtivo da agricultura se não houvesse estímulo governamental. Neste sentido, Guimarães (1979, p. 304) destaca a ação do Estado,

[...] foi a partir da década de 1970, sob o estímulo de amplo programa de incentivos governamentais, que a demanda de equipamentos agrícolas tomou o maior impulso, coincidindo com a instalação no país de diversas fábricas de equipamentos, em sua maioria subsidiárias de empresas multifuncionais. A produção de tratores, iniciada na década anterior, elevou-se rapidamente, atingindo seu nível máximo em 1975, quando foram produzidas 59.851 unidades. Outros equipamentos agrícolas mais complexos, como colhedeiras e combinadas automotrizes, passaram também a ser produzidas em ritmo ascendente por empresas estabelecidas no país. (Grifo nosso). 
A ação governamental brasileira auxiliou o processo de modernização da agricultura. Tal amparo ao capital viabilizou o crescimento produtivo alicerçado ao grande proprietário de terras, como também, relacionado às culturas essenciais para o setor agroindustrial, deixando a margem os pequenos produtores.

O apoio governamental a atuação do capital estrangeiro se deu por motivos ideológicos e principalmente pelo interesse dos grupos dominantes. Sendo assim, Graziano da Silva (1982, p. 30) nos faz pensar que, "No caso brasileiro, fica mais ou menos claro por que as políticas de estímulo à modernização não atingiram as pequenas unidades agrícolas, especialmente as que se dedicam à produção de gêneros alimentícios de primeira necessidade”.

A viabilização da modernização da agricultura obteve ainda mais êxitos com a instalação das indústrias para a produção dos equipamentos, fertilizantes e produtos químicos em geral, bem como, maquinários e implementos agrícolas avançados (GUIMARÃES, 1979). Desta forma, Matos e Pessôa (2012, p. 1) assinalam ainda que a modernização da agricultura no Brasil "Só foi possível no contexto de uma conjuntura política em que o Estado foi o condutor, por meio de investimentos em pesquisas científicas, com a criação de órgãos como a EMBRAPA, programas e créditos agrícolas".

A atividade agrícola adaptou-se as exigências do capital, tal processo indica o momento em que a indústria capitalista passou a dominar (CLEPS JUNIOR, 1998). Destaca-se a afirmação de Graziano da Silva (1996, p. 30), que ressalva que tal fato só foi possível “[...] especialmente por mudanças tecnológicas e de ruptura das relações de produção arcaicas e do domínio do capital comercial". Ainda nesta abordagem, Matos e Pessôa (2012, p. 2) enfatizam que,

\footnotetext{
Desse modo, a agricultura moderna, entendida como a incursão cada vez mais intensa das inovações tecnológicas e das metamorfoses da relação capital x trabalho, tem propagado no Brasil, notadamente no Cerrado, como um modelo que altera as condições econômicas, contribuindo para o aumento da produção agrícola do país. Os dados quantitativos e qualitativos da produção agrícola, como se essa produção pertencesse a todos, forjam uma falsa imagem das reais consequências que o agronegócio gera para os biomas, para os trabalhadores e a sociedade de um modo geral.
}

A modernização da agricultura viabilizada pelas ações das corporações transnacionais juntamente com o apoio governamental brasileiro, promoveram intensas reorganizações produtivas, econômicas, ambientais e sociais. Neste sentido, tal movimento caracterizou impactos em todo o processo de organização/reorganização socioespacial do país. Ao considerar os desafios promovidos pelo conjunto das ações e medidas articuladas deve-se interpretar e problematizar as consequências deste processo para o setor produtivo enfocado neste trabalho: a pecuária de leite bovino. 


\section{A PECUÁRIA DE LEITE BOVINO FRENTE AS LIMITAÇÕES, AS DIFICULDADES E AS EXPECTATIVAS PARA O DESENVOLVIMENTO LOCAL/REGIONAL}

Apesar dos excelentes resultados técnicos, com o crescimento exponencial de algumas produções e, da produtividade, enfatiza-se que ainda existem problemas estruturais e de nível particular a cada atividade e/ou região que é desenvolvida a produção. Confirma-se que os sucessos concebidos pela transformação voraz da agricultura foram expressivos a uma parcela reduzida das produções agrícolas e pecuárias.

Todavia, o setor agropecuário foi dotado de grandes resultados positivos e amplamente vantajosos para os grupos transnacionais e os grandes proprietários de terra. Tais resultados "positivos" decorrem da expansão de algumas atividades, como por exemplo, no setor agrícola, ressalta-se o cultivo de soja e de cana-de-açúcar, na pecuária, aponta-se o crescimento da pecuária de corte bovino e suíno, na silvicultura, destaca-se a expansão do cultivo de eucalipto e seringueiras, os quais foram viabilizados pela modernização da agricultura.

As cadeias produtivas dos mais variados setores estão passando por profundas mudanças para atender a demanda do complexo agroindustrial dominante, a qual é calcada pela imposição da modernização alicerçada pelos interesses dos grupos transnacionais produtores de insumos, maquinários, dispersores de tecnologias. Nesse aspecto, Chavas (2001, p. 265) relata,

Over the centuries, the production process has evolved from simple forms of food gathering
(e.g., hunting and fishing) to complex biotechnologies (e.g., genetic engineering). Hunting
and fishing activities remain important sources of food in some parts of the world, and
extensive production systems (e.g., pastoralism) still play significant roles in food
production where population density is low and/or land productivity is low. However,
intensive forms of production are now commonly found around the world. These intensive
forms have typically been associated with high population densities, productive land, and
rapid technological progress.

Chavas (2001, p. 265) apresenta que as formas intensivas de produção, na atualidade, são comumente desenvolvidas por meio do rápido progresso técnico, destacando as biotecnologias complexas, a Engenharia Genética, as quais foram articuladas para satisfazer as necessidades dos países com altas densidades populacionais, aliado a existência de terras produtivas.

Neste apontamento, destaca-se a realidade vivenciada pelo produtor rural. O alicerce da cadeia produtiva é o produtor rural e para se manter diante as exigências e, até mesmo, conseguir se sustentar frente ao que é imposto pela indústria, vivencia uma dependência do complexo agroindustrial, que em sua maioria, são de capital de origem internacional. Enfocando a cadeia produtiva de leite bovino, Alvarenga (1998, p. 149) destaca, 
No horizonte econômico do país, onde pipocam tantos flashes, utilizando lâmpadas nacionais e estrangeiras, há um homem em perplexidade chapliniana ${ }^{1}$, diante dos dados, cifras e promessas. Quieto, na penumbra, vez por outra acusado de alguma coisa que não entende bem: é o produtor de leite.

Deste modo, evidencia que o produtor rural, em especial, o produtor de leite, vive um ciclo que é articulado para atender a demanda e os interesses do capital. O produtor não adaptando-se, independentemente das condições técnicas e, principalmente financeiras, é alijado da cadeia produtiva.

A este respeito, sabe-se que na atualidade, os produtores rurais que se adequaram a tendência do agronegócio possuem como ordem a especialidade produtiva. Mazoyer e Roudart (2010, p. 425) sobre a realidade dos estabelecimentos produtores agropecuários apresentam,

Hoje os estabelecimentos são, na maioria das vezes, inteiramente especializados num número muito reduzido de produções particularmente rentáveis. São equipadas com tratores pesados e grandes máquinas, fazem maciçamente apelo aos adubos minerais, aos produtos fitossanitários, aos alimentos do gado, a variedades de plantas e raças de animais altamente selecionados. Esses estabelecimentos vendem a quase totalidade de seus produtos nos mercados multirregionais e multinacionais e compram a maior parte de seus meios de produção, sendo que o autoconsumo e o autoabastecimento ocupam somente um lugar limitado.

A reorganização produtiva resultante da demanda das agroindústrias favoreceu a articulação do setor agropecuário e, por conseguinte, mudanças estruturais na produção, resultando impactos sociais. Schneider (2010, p. 102) corrobora com essa passagem enfatizando que,

As mudanças demográficas e econômico-produtivas tiveram enorme repercussão sobre a diversidade social no meio rural brasileiro desde a década de 1970. De um lado, formou-se um grupo de produtores modernizados, com acesso a tecnologias, altamente mecanizados e inseridos nas cadeias de produção de grãos (notadamente, soja, milho e trigo), carnes (aves e suínos), cana-de-açúcar, silvicultura, entre outros. De outro, consolidou-se e ampliou-se o grupo formado e integrado por uma miríade de produtores e residentes no meio rural que foram alijados desse processo, permanecendo na condição de pobreza e na precariedade.

A expansão do uso de novos métodos produtivos e o incremento tecnológico para o desenvolvimento da agropecuária é uma realidade devido os movimentos que os grupos detentores do capital realizaram nas últimas décadas. A consequência deste processo é o crescimento produtivo.

Contudo, algumas atividades, como, por exemplo, a pecuária de leite bovino ficou à margem do sucesso dinamizado pela modernização da agricultura. Vilela; Bressan e Cunha (2001, p. 9) ressaltam, que "Qualquer que seja o índice de eficiência que se olhe, o setor de lácteos aparece à frente de uma lista de exceções no processo de modernização das atividades agroindustriais".

\footnotetext{
${ }^{1} \mathrm{O}$ termo deriva de Chaplin, sobrenome do ator Charlie Chaplin.
} 
Surgem algumas indagações referente a produção de leite no país, como por exemplo, por que o governo não auxilia de forma eficaz os produtores para fomentar a modernização e o incremento produtivo? Por que não existe uma regulamentação adequada de preços do valor do litro coletado pelos laticínios? Quais as pretensões do governo devido às poucas políticas públicas voltadas para esta atividade?

Desta forma, demonstra-se que as políticas públicas para favorecer o desenvolvimento da pecuária leiteira no Brasil foram comedidas em relação ao setor agrícola. Além disso, não foram eficazes para conduzir o incremento desta atividade para competir com as maiores nações produtoras.

A articulação do complexo agroindustrial, tanto de origem internacional quanto nacional, aliado as cooperativas, promoveu a dinamização da pecuária de leite bovino no cenário produtivo brasileiro. O resultado das ações idealizadas pelo setor privado culminou de certa forma, no incremento produtivo (SOUTO, 2016).

O setor leiteiro está vivenciando desde os anos de 1990 algumas alterações. A este respeito, Souza (2013, p. 9) enfatiza que, “As grandes transformações que estão ocorrendo na industrialização e produção de leite no Brasil, colocam o país no centro da dinâmica de um dos setores mais importantes na produção de alimentos no mundo".

Ao associar o panorama produtivo de leite bovino que vivemos hoje, deve-se levar em consideração as transformações ocasionadas em todo o setor agropecuário. A modernização das atividades realizadas no campo, juntamente com a expansão dos complexos agroindustriais, aliado ao interesse do capital externo, como no caso das multinacionais implantadas no país, os quais ditam as regras. Todavia, problematizar deve ser uma saída e dialogar é um fundamento. Assim, iremos analisar algumas políticas públicas adotadas.

\subsection{O desenvolvimento de políticas públicas para a produção de leite: analisando as medidas adotadas e as perspectivas para o setor}

A produção de leite está obtendo avanços nos quesitos de quantidade produzida, produtividade e qualidade. Contudo, essa atividade nem sempre foi adequada e, sobretudo, favorável tanto para o produtor quanto para o consumidor. A este respeito, Souza (1999, p. 41) salienta que as ações do Estado impactaram esta produção, enfatizando que,

A expansão ou retração da produção leiteira está relacionada às políticas econômicas adotadas. Ao analisar a conjuntura econômica brasileira, observam-se reduções da produção de leite no início dos anos 1980, em função da crise econômico-financeira ocorrida nesse período. Esse foi um período conturbado, cujos efeitos para o setor leiteiro foram de atraso tecnológico, baixa competitividades e perda de mercados. Dentre os fatores que causaram esta situação desfavorável, destacam-se: endividamento externo, déficit fiscal, inflação e redução de investimentos. 
Aliada à conjuntura econômica brasileira na década de 1980, as rudimentares técnicas utilizadas no processo produtivo do leite, a baixa produtividade, como também, a regulamentação do valor do litro do leite pelo governo ${ }^{2}$, resultaram em grandes dificuldades para o produtor.

Deste modo, deve-se salientar que, as ações governamentais são essenciais para a dinamização desta atividade. Sendo assim, Breitenbach e Souza (2013, p. 2), apontam as mudanças no setor produtivo de leite bovino resultantes das medidas adotadas pelo setor público,

A produção de leite no Brasil - bem como a maioria das produções ligadas ao agronegócio passou por importantes transformações nas últimas décadas do século passado, mas principalmente nos anos de 1990, decorrentes, especialmente, de transformações na economia mundial (formação e consolidação de blocos econômicos, globalização do comércio e liberalização comercial). No plano institucional nacional houve, nesta década, a desregulamentação do mercado (fim da participação do Estado na formação do preço), a abertura do mercado doméstico, o sucesso do Plano Real na estabilização da economia, a extinção do Programa de Tíquete do Leite $^{3}$ (instituído na década anterior e que transformou o Estado em grande comprador do produto final), e implantação do Plano Nacional de Qualidade do Leite 4 .

Dentre as ações governamentais que tiveram grande impacto para o setor pecuário de leite bovino, ressalta-se a regulamentação do tabelamento do preço pelo governo brasileiro. A este respeito, Vilela et al $(2017$, p. 7$)$ assinalam que,

A revolução tropical da década de 1990, conhecida como a safra dos trópicos, foi rica para a agricultura, mas nem tanto para a pecuária leiteira. Foi a era do livre mercado, quando a histórica Portaria 43, da extinta Sunab, decreta o fim do tabelamento do leite no Brasil, pondo fim a um ciclo que durou meio século. Isso trouxe distorções que prejudicaram a atividade leiteira naquele momento. Embora a abertura econômica tenha provocado grande desnacionalização das empresas brasileiras com a invasão de produtos importados, a entrada de lácteos forçou a modernização e a profissionalização da atividade.

A reorganização do setor produtivo de leite bovino, a partir da década de 1990 é enfatizada por Clemente, Santos e Hespanhol (2003, p. 66), destacando as reformulações do sistema agroindustrial do leite, a qual ocorreu devido,

\footnotetext{
${ }^{2}$ De acordo com Clemente e Hespanhol (2009, p. 161) a intervenção estatal no tabelamento dos preços do leite entre os anos de 1945 e 1991 ocorreu sob alegação de garantir preços acessíveis às camadas mais pobres da população, porém, esta medida não foi capaz de garantir o atendimento adequado por leite para o público esperado.

${ }^{3}$ Em 1986 é criado o PNLCC (Programa Nacional do Leite para Crianças Carentes), conhecido como "programa do tíquete do leite", voltado para crianças de até 7 anos de idade de famílias com renda mensal de até 2 salários mínimos. (COHN, 1996).

${ }^{4}$ Implementação de normas sanitárias mais rígidas para o setor por parte do Governo Federal. A implementação do PNMQL teve o intuito de melhorar as condições sanitárias do setor a partir de mudanças na legislação. Foi lançado pelo Ministério da Agricultura a Portaria 56, que exigia a granelização de toda a coleta até junho de 2002. Tendo em vista as dificuldades dos produtores em atender as novas exigências, as designações da Portaria 56 foram proteladas, e posteriormente, lançada a Portaria 51, que previa para julho de 2005, a granelização total do setor lácteo. Salienta-se que a Instrução Normativa 51 entrou em vigor dia 01 de julho daquele mesmo ano. Em face das dificuldades em atender aos requisitos sanitários, o Departamento de Inspeção de Produtos de Origem Animal (DIPOA), órgão vinculado ao Ministério da Agricultura, concedeu um prazo de seis meses para a adequação aos novos parâmetros sanitários de qualidade do leite. (CLEMENTE e HESPANHOL, 2009, p. 186).
} 
[...] abertura da economia e da desregulamentação do setor pelo governo federal. A desregulamentação após 46 anos de controle estatal afetou desde o produtor até o consumidor final. Durante o período de intervenção governamental - 1945-1991 - o SAG do leite pouco se modernizou e o consumidor não tinha à sua disposição a variedade de produtos lácteos que tem atualmente. Com a desregulamentação o produtor deixou de contar com um preço fixo para o produto uma vez que os preços passaram a ser estabelecidos no mercado, o qual é dominado por grandes empresas oligopólicas.

Dentre as principais dinamizações que primaram o que se pode chamar de elementar melhoria, para a pecuária de leite bovino, como, a formação e a consolidação de blocos econômicos, a globalização do comércio e liberalização comercial, o fim da participação do Estado na formação do preço do litro do leite e implantação do Plano Nacional de Melhoria da Qualidade do Leite (PNMQL), implementando normas sanitárias mais rígidas para o setor, foram fundamentais para os produtores conseguirem aprimorar a sua atividade, como também, ampliar a produção.

Desta forma, fica evidente que as políticas públicas para o setor pecuário leiteiro não foram capazes de contribuir para a melhoria desta atividade. Embora nos últimos anos tenha ocorrido o crescimento da quantidade produzida de leite no Brasil, observa-se que, de modo geral, o governo brasileiro pouco tem feito para auxiliar de maneira efetiva o desenvolvimento deste setor.

$\mathrm{Na}$ atualidade, uma medida governamental que poderá prejudicar ainda mais esta atividade produtiva refere-se ao encerramento da cobrança tarifária sobre a importação de leite em pó, integral ou desnatado da União Europeia e da Nova Zelândia. Esta medida foi uma decisão que ocorreu no início do segundo mês de governo de Jair Messias Bolsonaro, dia 06 de fevereiro de 2019, a Secretaria Especial de Comércio Exterior e Assuntos Internacionais do Ministério da Economia, publicou no Diário Oficial da União ${ }^{5}$ (BRASIL, 2019, p. 28),

[...] 1. Encerrar a revisão da medida antidumping ${ }^{6}$ instituída pela Resolução CAMEX $\mathrm{n}^{\circ} 2$, de 5 de fevereiro de 2013, iniciada por intermédio da Circular SECEX n 7, de 5 de fevereiro de 2018, publicada no Diário Oficial da União (D.O.U) de 6 de fevereiro de 2018, sem prorrogação da referida medida, uma vez que não houve comprovação da probabilidade de retomada de dumping nas exportações da União Europeia e da Nova Zelândia para o Brasil de leite em pó, integral ou desnatado, não fracionado, classificado nos itens 0402.10.10, 0402.10.90, 0402.21.10, 0402.21.20, 0402.29.10 e 0402.29.20 da Nomenclatura Comum do MERCOSUL-NCM, e do dano à indústria doméstica decorrente de tal prática, no caso de extinção da medida antidumping em questão, nos termos do art. 106 do Decreto n 8.058, de 2013. (Grifo nosso).

\footnotetext{
${ }^{5}$ [...] nos termos do acordo sobre a Implementação do Artigo VI do Acordo Geral sobre Tarifas e Comércio - GATT 1994, aprovado pelo Decreto Legislativo ${ }^{\circ} 30$, de 15 de dezembro de 1994, e promulgado pelo Decreto ${ }^{\circ} 1.355$, de 30 de dezembro de 1994, de acordo com o disposto no art. 5 do Decreto $\mathrm{n}^{\circ}$ 8.058, de 26 de julho de 2013, e tendo em vista o que consta do Processo MDIC/SECEX 52272.001196/2017-18 e do Parecer $\mathrm{n}^{\circ} 1$, de 5 de fevereiro de 2019, elaborado pelo Departamento de Defesa Comercial e Interesse Público - DECOM desta Secretaria.

${ }^{6}$ Os direitos antidumping têm como objetivo evitar que os produtores nacionais sejam prejudicados por importações realizadas a preços de dumping, prática esta considerada como desleal em termos de comércio em acordos internacionais. (Ministério da Economia, Indústria, Comércio Exterior e Serviços, BRASIL, 2019).
} 
De acordo com o Ministério da Economia, Indústria, Comércio Exterior e Serviços (2019) a aplicação de medidas de defesa comercial, como no caso da medida antidumping, a qual prevê evitar que os produtores nacionais sejam prejudicados por importações realizadas a preços de dumping, requer,

[...] no âmbito de um processo administrativo, seja realizada uma investigação, com a participação de todas as partes interessadas, onde dados e informações são conferidos e opiniões são confrontadas, para que o Departamento possa propor a aplicação de uma medida ou o encerramento de uma investigação sem imposição da mesma. Nos casos de dumping, a investigação deve comprovar a existência de dumping, de dano à produção doméstica e de nexo causal entre ambos. A investigação deverá ser conduzida de acordo com as regras estabelecidas nos Acordos da $\mathrm{OMC}$ e na legislação brasileira. Tais regras buscam garantir ampla oportunidade de defesa a todas as partes interessadas e a transparência na condução do processo.

Mediante a importância da organização das medidas de defesa comercial, enfatiza-se a decisão do governo federal, de encerrar a cobrança tarifária sobre a importação de leite em pó, integral ou desnatado da União Europeia e da Nova Zelândia, na publicação do dia 06 de fevereiro de 2019 no Diário Oficial da União (BRASIL, 2019, p. 30),

O produto objeto do direito antidumping é o leite em pó ou granulado, desnatado e integral, não fracionado, ou seja, acondicionado em embalagens não destinadas a consumo no varejo, originário da Nova Zelândia e da União Europeia. [...] importado em sacos de $25 \mathrm{~kg}$, tendo como destinação dois fins específicos: indústrias alimentícias, que o utilizam como matéria-prima na produção de chocolates, achocolatados, sorvetes, biscoitos, doces, massas entre outras; ou indústrias de laticínios, que o fracionam a fim de que seja comercializado a atacadistas e varejistas de pequeno, médio e grande porte. A matéria-prima do produto objeto do direito antidumping é o leite in natura, produto oriundo da ordenha completa, ininterrupta, em condições de higiene, de vacas sadias, bem alimentadas e descansadas.

As políticas públicas brasileiras dirigidas para atender a demanda do capital, são estrategicamente organizadas considerando os interesses políticos e, sobretudo, a partir das alianças com os complexos agroindustriais multinacionais, englobando o atendimento das necessidades externas. A este respeito, Ianni (1984, p. 242) relata que,

Pode-se dizer que o poder público tem sido levado a tomar decisões, criar órgãos, desenvolver políticas que influenciam bastante a agricultura, segundo os interesses da indústria, comércio e banco. A agricultura se desenvolve e se transforma segundo interesses do capital centrado na indústria, nacional e estrangeira. Ao longo da história, o campo é subordinado à cidade em escala crescente. Há mesmo uma industrialização do campo, seja em termos estritamente econômicos, seja em termos sociais e culturais. No campo, o capitalismo se desenvolve de forma extensa e intensa, conquistando e reconquistando fronteiras. [...] E é essa dominação que garante a influência da questão agrária no Estado. $\mathrm{O}$ caminho de ida é sempre o caminho de volta. Assim como a cidade vai ao campo, o campo entra pela cidade. Tanto em sentido histórico como teórico, as diversas formas adquiridas pelo Estado, bem como suas principais rupturas, têm muito a ver com a questão agrária. São vários os aspectos da sociedade agrária que revelam a presença desta no Estado brasileiro. 
Os interesses ligados aos processos de produção, reprodução e acumulação capitalista viabilizam profundas transformações e, especialmente, impactos em toda a sociedade. No tocante a cadeia produtiva do leite, como também nos demais setores produtivos, verifica-se que, não somente as ações internas, ou seja, as políticas públicas e medidas do setor privado adotadas no país, como também, o contexto relacionado aos processos externos, por meio dos interesses governamentais dos países centrais e, sobretudo, pelas corporações transnacionais, ditam as regras da agricultura e do sistema agroindustrial como um todo.

Portanto, a pecuária de leite bovino, como se pode notar, passa por profundos impactos mediante as ações governamentais, as quais foram idealizadas sem preocupação com o que poderia acarretar no processo produtivo leiteiro. Mediante essa colocação, aponta-se que esta atividade é importante para o cenário econômico, contudo, não há notáveis ações governamentais que articulem e propiciem melhorias ao setor.

\section{CONCLUSÃO}

O desenvolvimento de ações públicas e privadas de origem nacional e internacional ocorreram com maior ênfase no Brasil após a metade do século XX. Tais procedimentos foram fundamentais para a organização, bem como, a reorganização espacial dos municípios brasileiros. Nesta abordagem, a produção do espaço com o enfoque da metamorfose que os meios capitalistas de produção proporcionaram deve ser considerada. Tal processo gera importantes reflexões acerca da necessidade de compreender os impactos tanto positivos quanto negativos, do passado, do presente e para o futuro.

Ressalta-se que a escala temporal de análise (1977 a 2017) foi marcada por significativas mudanças estruturais no país. Dentre as alterações, aponta-se a modernização das propriedades rurais, a melhoria da infraestrutura do campo e a expansão da urbanização. Neste período, houve o crescimento da área (ha) para a produção de algumas culturas, como, a soja e a cana-de-açúcar, a redução do uso de área para a pastagem, como também, para o cultivo de demais alimentos para o gado, o declínio da mão de obra rural, a expansão do êxodo rural. Em contrapartida, houve o crescimento da produtividade do leite, surgimento e expansão das unidades de agroindústrias leiteiras (locais, nacionais e multinacionais), implantação de regras e exigências para a qualidade sanitária e ambiental, entre outros processos.

É sabido que as ações públicas e privadas para o incremento produtivo da agricultura, historicamente, foram direcionadas para o setor agrícola. Assim, os produtores possuem maior subsídio, crédito e apoio público e privado, proporcionando a sua implementação/expansão e manutenção, deixando as demais atividades à margem. 
No que tange o cenário produtivo de leite bovino, deve-se destacar as ações que promoveram o incremento deste setor. Sendo assim, é possível apontar que ocorreu alguns processos para a evolução produtiva. Dentre as medidas e aprimoramentos, ressaltam-se o melhoramento genético do gado e a suplementação alimentar. Enfatiza-se a utilização de tecnologias para maior produtividade do leite, como a ordenha mecanizada, bem como, o uso de equipamentos para proporcionar maior segurança na qualidade e higiene de armazenamento do produto in natura, como os refrigeradores, além das técnicas de coleta, armazenagem e higiene de todo o processo produtivo.

Ressalva-se que, as exigências da Agência Nacional de Vigilância Sanitária (ANVISA) juntamente com a necessidade de qualidade do produto brasileiro, culminaram em uma maior inspeção e cumprimento de regras para a qualidade do produto ainda in natura, reduzindo os riscos de contaminação e aumentando a qualidade do produto.

Em contrapartida, para a manutenção desta atividade foi vital a ação do complexo agroindustrial leiteiro, pois o mesmo atuou/atua como dinamizador desta produção. Destaca-se que as maiores indústrias processadoras desta matéria prima no território brasileiro são, em sua maioria, vinculadas ao capital internacional.

A demanda por leite bovino pelas processadoras promove a necessidade da manutenção e expansão da produção de leite no cenário local e regional de onde estão instaladas. Entretanto, sabese que está ocorrendo a expansão de outras atividades agropecuárias e, consequentemente, para atender à necessidade das processadoras de leite, as propriedades produtoras de leite precisam aumentar a sua produtividade.

O aumento da produtividade é alicerçado pelo investimento que o produtor de leite é induzido a fazer em sua propriedade. Contudo, enfatiza-se que os produtores de leite muitas vezes possuem pouco capital para investir na melhoria de sua propriedade. Neste cenário, destaca-se que o produtor com o poder de capitalização maior sobressairá em relação ao produtor que possui dificuldades (financeiras).

Neste aspecto, deve-se ressaltar que os laticínios valorizam e pagam os produtores de acordo com o volume fornecido, como também, devido a qualidade do produto in natura, ou seja, há diferença no valor pago para o produtor que entregar maior volume e melhor qualidade (menos bactérias e mais gordura). Porém, sabe-se que, a diferenciação do valor pago pelo volume e qualidade faz com que o produtor de leite enfrente maiores dificuldades para desenvolver essa atividade.

Para tanto, ressalta-se que torna-se essencial o auxílio de ações e políticas públicas para contribuir na manutenção do desenvolvimento desta atividade. O desenvolvimento das políticas e ações públicas e privadas para o incremento dessa atividade gera retorno econômico e social. 
Portanto, verificou-se o desenvolvimento de ações e políticas que conduzem o incremento de algumas poucas atividades do setor agropecuário, deixando a margem o setor produtivo leiteiro. Devemos destacar as reflexões possibilitadas nessa investigação, as quais nos direcionam para a compreensão das inquietações que move esse setor produtivo, entendendo as preocupações, as aflições e, em alguns casos, o sucesso dos produtores de leite. Ainda nessa perspectiva, não podemos deixar de ressaltar que tais reflexões nos direcionam ainda para as metamorfoses espaciais que se fazem presentes a partir do desenvolvimento deste setor produtivo.

\section{AGRADECIMENTOS}

O presente trabalho foi realizado com apoio da Coordenação de Aperfeiçoamento de Pessoal de Nível Superior - Brasil (CAPES) - Código de financiamento 001.

\section{REFERÊNCIAS}

ALVARENGA, O. M. Agricultura brasileira: realidade e mitos. 1. ed. Rio de Janeiro: Revan, 1998. 288p.

BARRIOS, S. A produção do espaço. In: A construção do espaço. Org.: SOUZA, M. A. A. de; SANTOS, M. São Paulo: Nobel, 1986.

BRASIL. Decreto n. 9.064, de 31 de maio de 2017. Regulamenta a Lei $n^{\circ} 11.326$, de 24 de julho de 2006, que dispõe sobre a Unidade Familiar de Produção Agrária, que estabelece as diretrizes para a formulação da Política Nacional da Agricultura Familiar e empreendimentos familiares rurais. Diário Oficial da União, Poder Executivo, Brasília, DF, 31 mai. 2017. Disponível em: $<$ http://www.planalto.gov.br/ccivil_03/_Ato2015-2018/2017/Decreto/D9064.htm>. Acesso em: 17 jul. 2019.

BRASIL. Ministério da Economia, Indústria, Comércio Exterior e Serviços. Dumping e direito antidumping. 2019. Disponível em: $<$ http://www.mdic.gov.br/index.php/comercio-exterior/defesacomercial/205-o-que-e-defesa-comercial/1767-dumping-e-direitos-antidumping $>$. Acesso em: 10 fev. 2019.

BRASIL. Secretaria de Comércio Exterior. Circular $n^{0}$ 5, de 5 de fevereiro de 2019. Sessão de 06/02/2019. Diário Oficial da União, Brasília, DF, 2019. Disponível em: <https://www.jusbrasil .com.br/diarios/226958729/dou-secao-1-06-02-2019-pg-28?ref=goto>. Acesso em: 08 fev. 2019.

BREITENBACH, R; SOUZA, R. S. Estrutura industrial na cadeia produtiva do leite e a interferência no desenvolvimento regional. In: SEMINÁRIO INTERNACIONAL SOBRE DESENVOLVIMENTO REGIONAL. 6., 2013, Santa Cruz do Sul/RS, Anais... Santa Cruz do Sul: Universidade de Santa Cruz do Sul, 2013. P. 1-17.

BRUM, A. J. Modernização da agricultura: trigo e soja. 1. ed. Petrópolis: Vozes, 1988. 200p. 
CHAVAS, J. P. Structural change in agricultural production: economics, technology and policy. Handbook of Agricultural Economics, 2001. Disponível em: <https://aae.wisc.edu/aae641 /Ref/Chavas_Structural_Change_2001.pdf $>$. Acesso em: 20 jun. 2018.

CLEMENTE, E. C.; HESPANHOL, A. N. Reestruturação produtiva da pecuária bovina leiteira: da organização espacial-produtiva em "bacias leiteiras" ao "circuito espacial de produção". Geonordeste, v. 20, n. 1, p. 151-174, 2009.

CLEMENTE, E. C.; HESPANHOL, A. N. Reestruturação da cadeia produtiva do leite: a especialização do produtor é a solução? Campo-Território, Uberlândia, v. 4, n. 8, p. 180-211, 2009.

CLEMENTE, E. C.; SANTOS, J. C.; HESPANHOL, A. N. O sistema agroindustrial do leite nas Regiões de Presidente Prudente e Jales. Formação, Presidente Prudente, v. 1, n. 10, p. 65-77, 2003.

CLEPS JR, J. Dinâmica e estratégias do setor agroindustrial no cerrado: o caso do Triângulo Mineiro. 1998. 256 f. Tese (Doutorado em Geografia) - Instituto de Geociências e Ciências Exatas, Universidade Estadual Paulista Júlio de Mesquita Filho, Rio Claro, 1998.

COHN, A. Desigualdade, desenvolvimento social e políticas sociais no Brasil. 1. ed. São Paulo: Cedec, 1996. 102p.

ELIAS, D. Territorialização do capital no espaço agrário cearense. Geografia, Rio Claro, v. 30, n. 2, p. 223-241, 2005.

FOOD AND AGRICULTURE ORGANIZATION OF UNITED STATES - FAO. Rearing cattle produces more greenhouse gases than driving cars, UN report warns, n. 29, nov., 2006. Disponível em: $<$ http://www.un.org/apps/news/story.asp?newsID=20772\&CR1=warning $>$. Acesso em: 06 jun. 2016.

FOOD AND AGRICULTURE ORGANIZATION OF UNITED STATES - FAO. FAOSTAT. Livestock Primary. 2018. Disponível em: $<$ http://www.fao.org/faostat/en/\#data/QL $>$. Acesso em: 21 mar. 2020.

GRAZIANO DA SILVA, J. A modernização dolorosa: estrutura agrária, fronteira agrícola e trabalhadores rurais no Brasil. 2. ed. Rio de Janeiro: ZAHAR EDITORES, 1982. 192p.

GRAZIANO DA SILVA, J. A nova dinâmica da agricultura brasileira. 1. ed. Campinas: IE/UNICAMP, 1996. 211p.

GUIMARÃES, A. P. A crise agrária. 1. ed. Rio de Janeiro: Paz e Terra, 1979. 362p.

IANNI, O. Origens agrárias do estado brasileiro. 1. ed. São Paulo: Editora Brasiliense, 1984. $256 \mathrm{p}$.

INSTITUTO BRASILEIRO DE GEOGRAFIA E ESTATÍSTICA - IBGE. SIDRA. Pesquisa Pecuária Municipal. 2017. Disponível em: <http://www.sidra.ibge.gov.br/bda/pesquisas/ppm/>. Acesso em: 20 fev. 2018.

MATOS, P. F.; PESSÔA, V. L. S. A modernização da agricultura e os novos usos do território. Geo UERJ, Rio de Janeiro, v. 2, n. 22, p. 290-322, 2011. 
MAZOYER, M.; ROUDART, L. História das agriculturas no mundo: do neolítico à crise contemporânea. Tradução de Cláudia F. Falluh Baluino Ferreira. 1. ed. São Paulo: UNESP, 2010. $568 \mathrm{p}$.

MOREIRA, R. O que é Geografia. 2. ed. São Paulo: Editora Brasiliense, 1982. 87p.

SANTOS, M. A natureza do espaço. 4. ed. São Paulo: EDUSP, 2006. 392p.

SCHNEIDER, S. Reflexões sobre diversidade e diversificação - agricultura, formas familiares e desenvolvimento rural. RURIS - Revista do Centro de Estudos Rurais, Campinas, v. 4, n. 1, p. 85-131. 2010.

SOUTO, T. S. Agroindústria leiteira no município de Ituiutaba - MG: Organização/ reorganização socioespacial no período de 1960 a 2013. 2016. 143 f. Dissertação (Mestrado em Geografia) - Universidade Federal de Santa Maria, Santa Maria, 2016.

SOUTO, T. S.; BEZZI, M. L. As metamorfoses socioespaciais resultantes do incremento da produção de leite: uma análise desta atividade no município de Ituiutaba/MG no período de 1960 a 2013. Sociedade \& Natureza, v. 2, n. 28, p. 227-242, 2016

SOUZA, J. J. Notas sobre a indústria de laticínios no Brasil e seu processo de formação perante a economia mundial. CaderNAU. v. 6, n. 1, p. 1-10, 2013.

SOUZA, O. T. O setor leiteiro: políticas, competitividade e impactos da liberalização comercial nos anos noventa. 1999. 130 f. Dissertação (Mestrado em Economia Rural) - Universidade Federal do Rio Grande do Sul, Porto Alegre, 1999.

VILELA, D.; BRESSAN, M.; CUNHA, A. S. Cadeia de lácteos no Brasil: restrições ao seu desenvolvimento. Brasília: MCT/CNPq, 2001. 284p.

VILELA, D.; RESENDE, J. C.; LEITE, J. L. B.; ALVES, E. A evolução do leite no Brasil em cinco anos. Revista de Política Agrícola, v. 26, n. 1, p. 5-24, 2017. 